\title{
A Scoping Review of Inclusive Out-of-School Time Physical Activity Programs for Children and Youth With Physical Disabilities
}

\author{
Kelly P. Arbour-Nicitopoulos \\ University of Toronto and Holland \\ Bloorview Kids Rehabilitation Hospital
}

Amy C. McPherson

Holland Bloorview Kids Rehabilitation

Hospital and University of Toronto

\author{
Viviane Grassmann \\ and Krystn Orr
}

University of Toronto

Guy E. Faulkner

University of British Columbia

\section{F. Virginia Wright}

Holland Bloorview Kids Rehabilitation Hospital and University of Toronto

The objective of this study was to comprehensively evaluate inclusive out-ofschool time physical activity programs for children/youth with physical disabilities. A search of the published literature was conducted and augmented by international expertise. A quality appraisal was conducted; only studies with quality ratings $\geq 60 \%$ informed our best practice recommendations. Seventeen studies were included using qualitative $(n=9)$, quantitative $(n=5)$, or mixed $(n=$ 3 ) designs. Programs had a diversity of age groups, group sizes, and durations. Most programs were recreational level, involving both genders. Rehabilitation staff were the most common leaders. Outcomes focused on social skills/relationships, physical skill development, and psychological well-being, with overall positive effects shown in these areas. The best practice recommendations are consistent with an abilities-based approach emphasizing common group goals and interests; cooperative activities; mastery-oriented, individualized instruction; and developmentally appropriate, challenging activities. Results indicate that inclusive

\footnotetext{
Arbour-Nicitopoulos, Grassmann, and Orr are with the Faculty of Kinesiology and Physical Education, and McPherson, the Dalla Lana School of Public Health, University of Toronto, Toronto, ON, Canada. ArbourNicitopoulos, McPherson, and Wright are with the Holland Bloorview Kids Rehabilitation Hospital, Toronto, ON, Canada. Faulkner is with the School of Kinesiology, University of British Columbia, Vancouver, BC, Canada. Wright is also with the Dept. of Physical Therapy, University of Toronto, Toronto, ON, Canada. Arbour-Nicitopoulos (kelly.arbour@utoronto.ca) is corresponding author.
} 
out-of-school time physical activity programs are important for positive psychosocial and physical skill development of children/youth with physical disabilities.

Keywords: inclusion, participation, physical disability, physical literacy

Inclusion is a process that encourages individuals with a wide range of abilities to engage together in meaningful participation in an environment that fosters a sense of belongingness and autonomy (DePauw \& Doll-Tepper, 2000; Goodwin, 2003; Grenier, 2011). Inclusive physical activity (PA) aims to promote equal access and physical literacy opportunities (e.g., movement skills, motivation, and confidence; International Physical Literacy Association, 2016) for all children and youth (Rimmer et al., 2014). Inclusive PA is often regarded as a "socializing environment to teach interpersonal skills and physical competencies," (Martin, 2010, p. 298) particularly for those with disabilities, and can also serve as a means to enhance social connectedness and peer acceptance (Duncan, Duncan, \& Strycker, 2005; Martin \& Mushett, 1996).

Empirical findings have identified psychosocial and behavioral benefits of inclusive PA that occurs as part of school-based activities (e.g., physical education classes) for children and youth with physical disabilities including increased peer support (Goodwin, 2001), friendships (Grenier, 2011; Seymour, Reid, \& Bloom, 2009), and motor performance (Kalyavas \& Reid, 2003). Benefits have also been shown for typically developing peers and teachers who are involved in inclusive physical education programs, such as increased acceptance of, and competence in working with, a wide range of individual capabilities (Grenier, 2011; Obrusnikova, Block, \& Válková, 2003), and a greater sensitivity toward those with physical disabilities (Grenier, 2011; Obrusnikova et al., 2003; Seymour et al., 2009). However, inclusive physical education programs also face challenges (Block \& Obrusnikova, 2007), such as peer relationships being restricted to the school environment (Seymour et al., 2009) and not necessarily extending to the larger community (Castenada \& Sherril, 1999). More inclusive, PA opportunities are warranted for children and youth with physical disabilities and their typically developing peers to try to facilitate interactions outside of school hours that will enhance optimal social, cognitive, and physical development and potentially contribute to more successful functioning as an adult (Block \& Malloy, 1998; Castenada \& Sherril, 1999; Costin \& Jones, 1992; Parker \& Asher, 1987).

Out-of-school time PA programs provide a setting in which children and youth with physical disabilities can form meaningful relationships with typically developing peers. Out-of-school time programs often occur on school grounds but outside of school hours (e.g., before and after school programs), or at locations that are outside of the school setting (e.g., residential camps, not-for-profit clubs, such as the Young Men's Christian Association; Dzewaltowski, 2008; Wiecha et al., 2014). Such programs have the potential for tremendous reach within the community (Wiecha et al., 2014) and are associated with a variety of physical and psychosocial health benefits for children and youth (Beets, Beighle, Erwin, \& Huberty, 2009; Pate \& O'Neill, 2009), thus, making them a viable context for the inclusion of children and youth with physical disabilities.

This scoping review examined the research involving inclusion of children and youth with physical disabilities in out-of-school time PA programs. A 
comprehensive evaluation was conducted, which included both peer-reviewed published evidence and international expertise (Reid, Bouffard, \& MacDonald, 2012) on out-of-school time PA programs for children and youth with physical disabilities and those who are typically developing. This scoping review addressed the following questions:

- What are the characteristics of inclusive, out-of-school time PA programs for school-aged children and youth (i.e., settings, activity modes, program duration, instructor expertise, types of program/activity modifications, how inclusion is defined)?

- What outcomes are associated with inclusive out-of-school time PA programs?

- What best practices can be recommended for each identified outcome to enhance the success of inclusive out-of-school time PA programs for schoolaged children and youth?

\section{Methods}

Given the uncertainty about the nature and extent of evidence that exists on inclusive, out-of-school time PA programs for school-aged children and youth with physical disabilities, the six-stage framework developed by Arksey and O'Malley (2005) and updated by Levac, Colquhoun, and O'Brien (2010) was used to comprehensively map the literature by (a) identifying the research question(s); (b) identifying the relevant studies; (c) selecting studies; (d) extracting data; (e) collating, summarizing, and reporting the results; and (f) consulting experts.

\section{Expert Panel}

Prior to conducting the review, an expert panel was formed to ensure credibility and thoroughness of the findings and best practice recommendations. Seven researchers with expertise in inclusive PA for children and youth with physical disabilities from Canada, the United States, The Netherlands, and Australia were involved in the identification of relevant studies and discussion of the interpretations of the findings and, where available, the best practice implications. Details on experts' roles within these stages are provided in the corresponding sections below.

\section{Search Strategy}

An extensive search was conducted by one author (V.G.), with the assistance of an academic librarian of peer-reviewed articles published between 1980 and July 2016 using seven databases: SPORTDiscuss, Physical Education Index, ERIC, CINAHL, MEDLINE, PsychINFO, and Embase. The emergence of out-of-school time inclusive PA models in the 1980s (Reid, 2003) directed our team's decision to begin the search no earlier than 1980. Search terms related to physical disabilities (e.g., cerebral palsy), PA (e.g., sport), age (e.g., adolescence), and inclusion (e.g., integration; see Supplementary Material [available online]). A subsequent hand search of two key journals (Therapeutic Recreation Journal and Adapted Physical 
Activity Quarterly) and reference lists of all included papers was conducted by two authors (V.G. and K.O.) to uncover additional papers.

\section{Study Selection}

Study inclusion criteria were as follows: (a) primary focus on school-aged children and/or youth (mean sample age $\leq 18$ years); (b) inclusion of at least one child/youth with a physical disability (i.e., a mobility and/or sensory impairment) and one typically developing child/youth; (c) peer-reviewed original studies of qualitative, quantitative, or mixed design; (d) focus on an existing PA program or an intervention that was examined as part of an experimental design (herein described as "program"); (e) situated outside of school hours; and (f) written in English.

\section{Screening}

Figure 1 outlines the screening process. Articles resulting from the search process were imported into the EndNote database management system and duplicates removed. To ensure reliability during the screening process, a calibration exercise (Kastner et al., 2012) was conducted. Using the study inclusion/exclusion criteria, four reviewers (K.A.N., V.G., K.O., and A.L.) screened a randomly selected 5\% of the titles and abstracts of the citations, and then discussed discrepancies in screening and/or eligibility criteria decisions. The four reviewers then independently screened the remaining $95 \%$ of the search (each reviewer screened a randomly allocated $23.75 \%$ of these citations) based on title and abstract. Hand searches of key journals and the reference lists of all eligible articles were reviewed by two of the authors (V.G. and K.O.). The remaining authors and the seven experts were sent electronic copies of the included articles at this time to verify the thoroughness of the articles selected and provide the citations of any articles missing from the list.

\section{Data Extraction and Analysis}

A data extraction chart (Table 1) was created, reviewed, and finalized by all authors. Three reviewers (V.G., K.O., and K.A.N.) then extracted pertinent information from the eligible studies in a stepwise fashion (i.e., one reviewer at a time) to ensure accuracy. This information consisted of characteristics relating to the (a) study, (b) target population, and (c) PA program, as well as (d) operationalization of the term "inclusion" (if available) and (f) reported analyses. From the full data extraction chart, a summary chart was created by two reviewers (V.G. and K.O.) that grouped results under the main outcomes assessed in each study. Both summary and full data charts were circulated among the authors, after which two meetings and a series of online discussions were held to discuss the results. Based on these group discussions, the main outcomes of the included studies were categorized into four key areas of associated impact—-social skills and relationships, physical skill development, psychological well-being, and participation in PA.

\section{Evaluation of Methodological Quality}

Although evaluation of study quality is not a typical part of a scoping review, the wide differences in methodological rigor in the identified studies became rapidly 


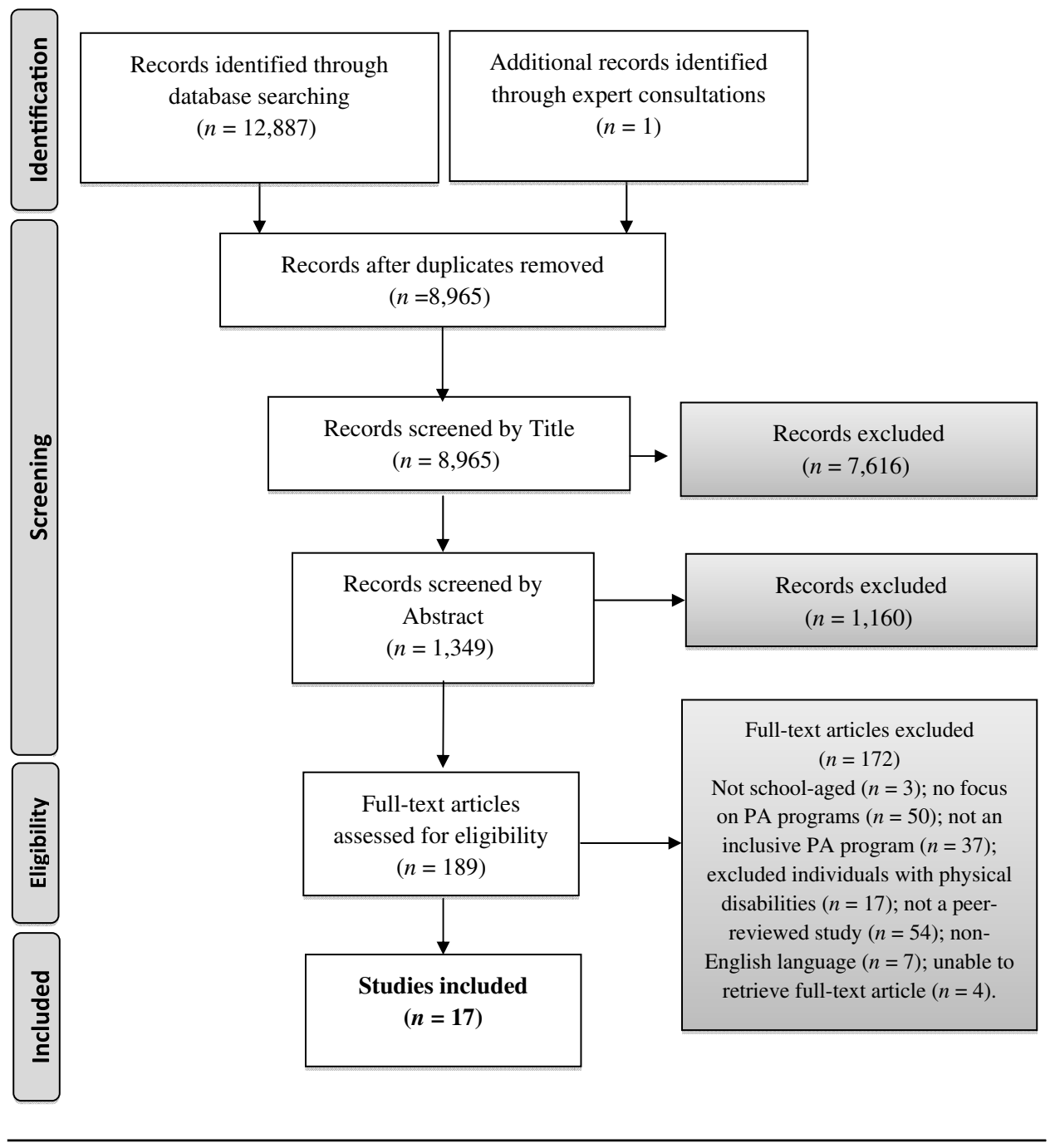

Figure 1 - Summary of screening process. PA = physical activity.

apparent. As noted by Glegg, Tatla, and Holsti (2014) in their scoping review that included a quality evaluation component, they were able to both "map the breadth" of work in the area so that the current state of knowledge is fully available for practitioners' consideration, and also guides the recommendation formation and next steps of research by direct reference to the strength of existing evidence. Three reviewers (V.G., K.O., and K.A.N.) independently appraised the quality of each of the included studies (53.5\% agreement) using a 16-item quality assessment tool that can be applied to quantitative, qualitative, and mixed-method studies (Sirriyeh, Lawton, Gardner, \& Armitage, 2012). Consensus was obtained on rating discrepancies through group discussion. This quality assessment tool has 


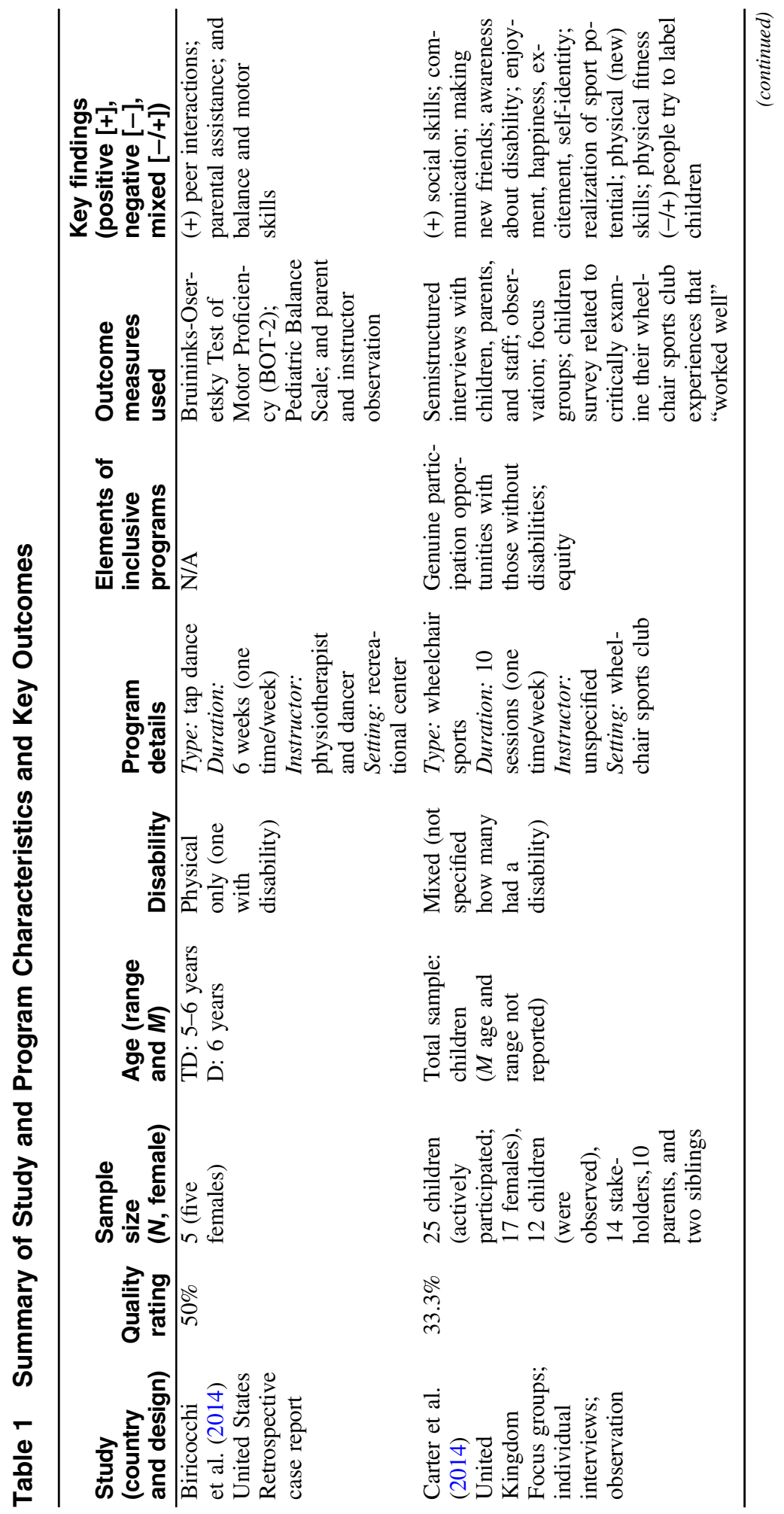




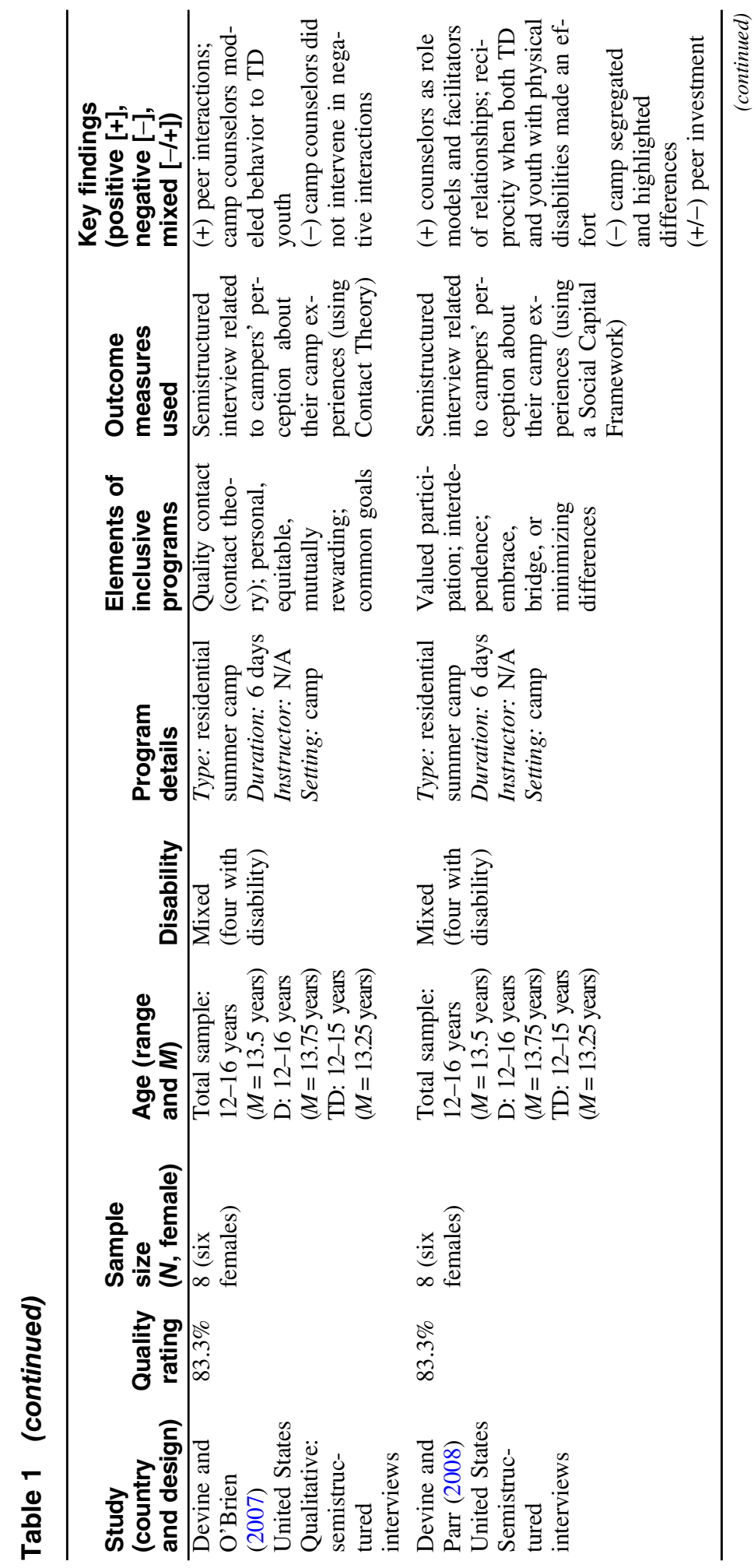




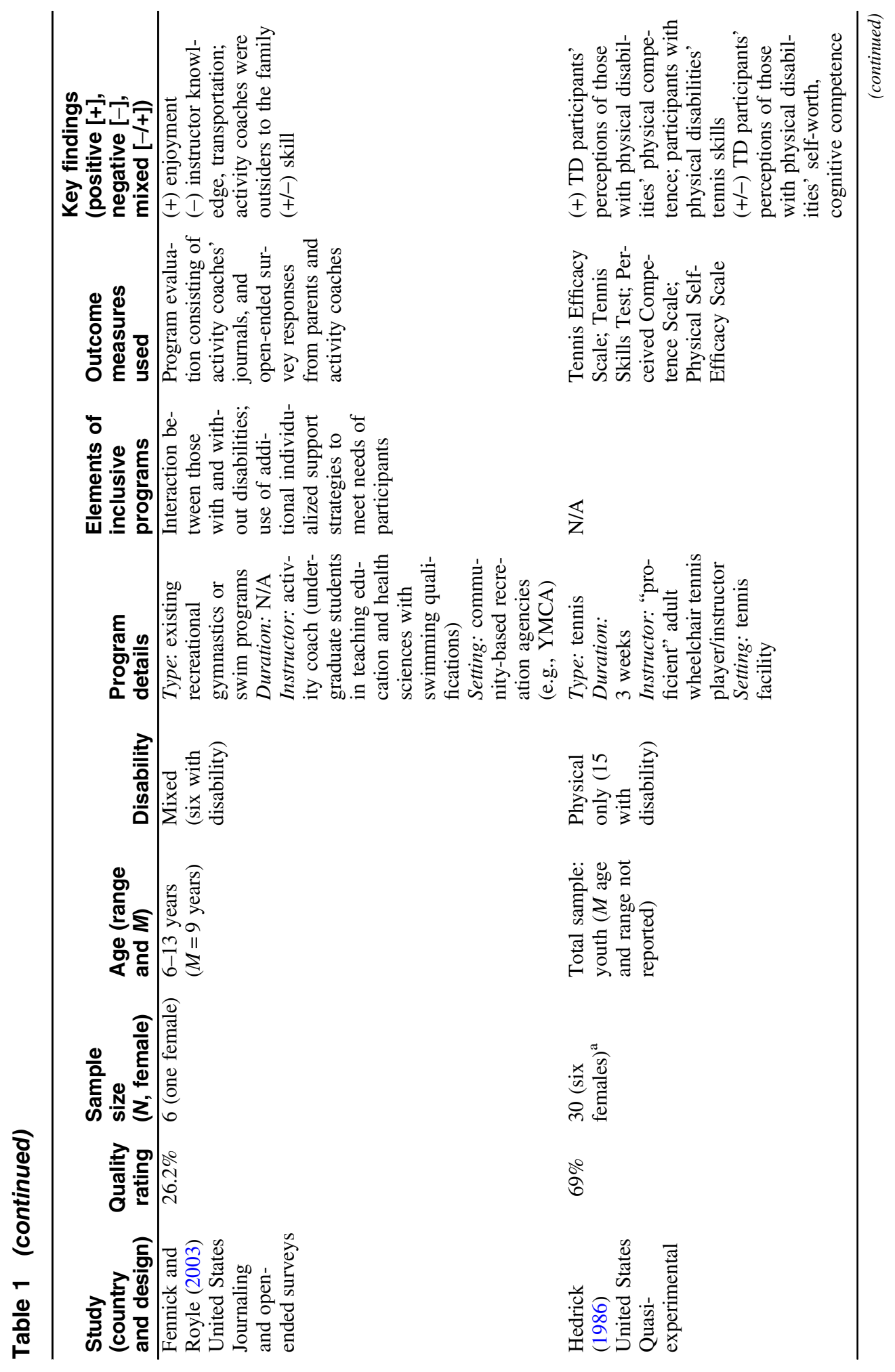




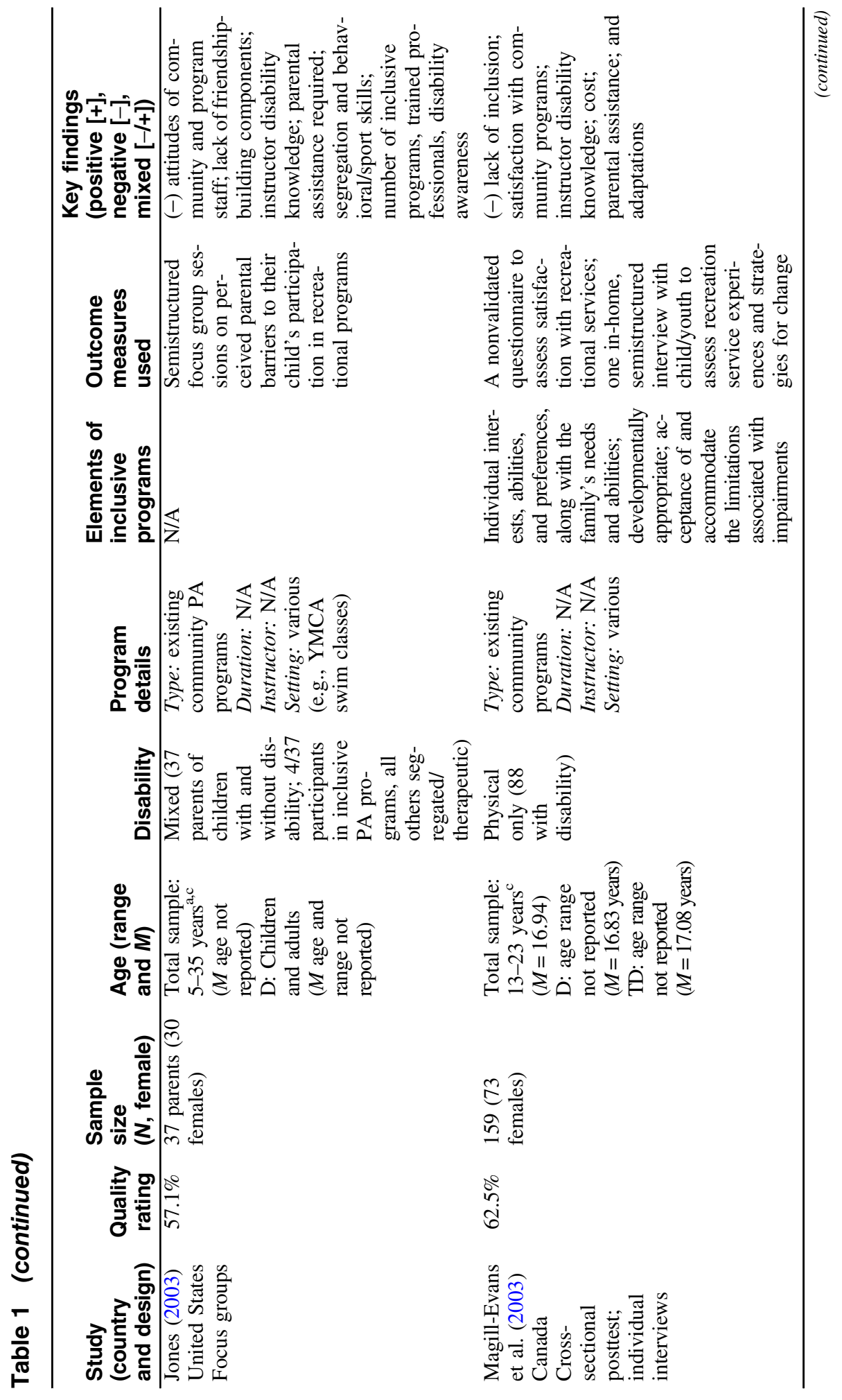




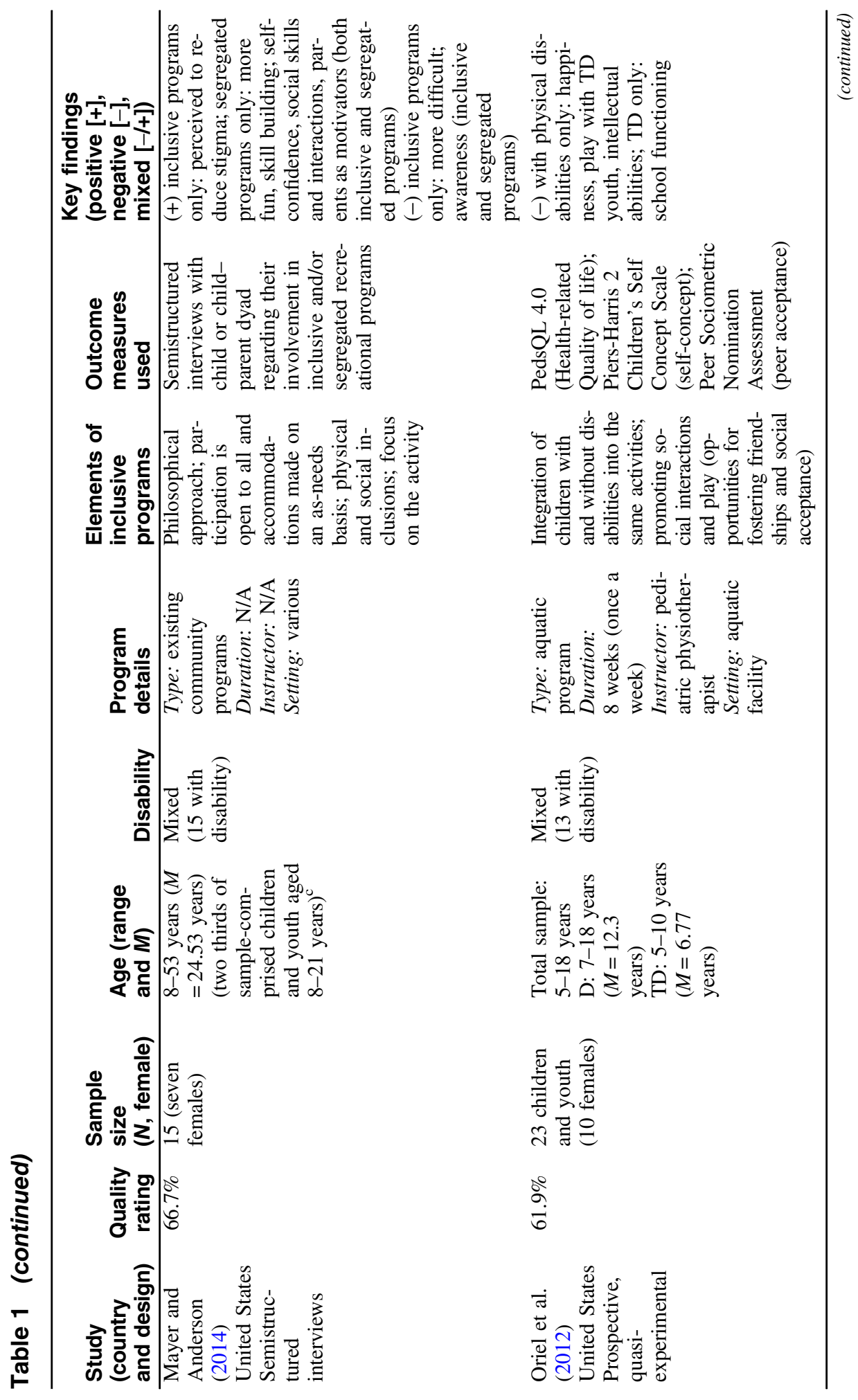




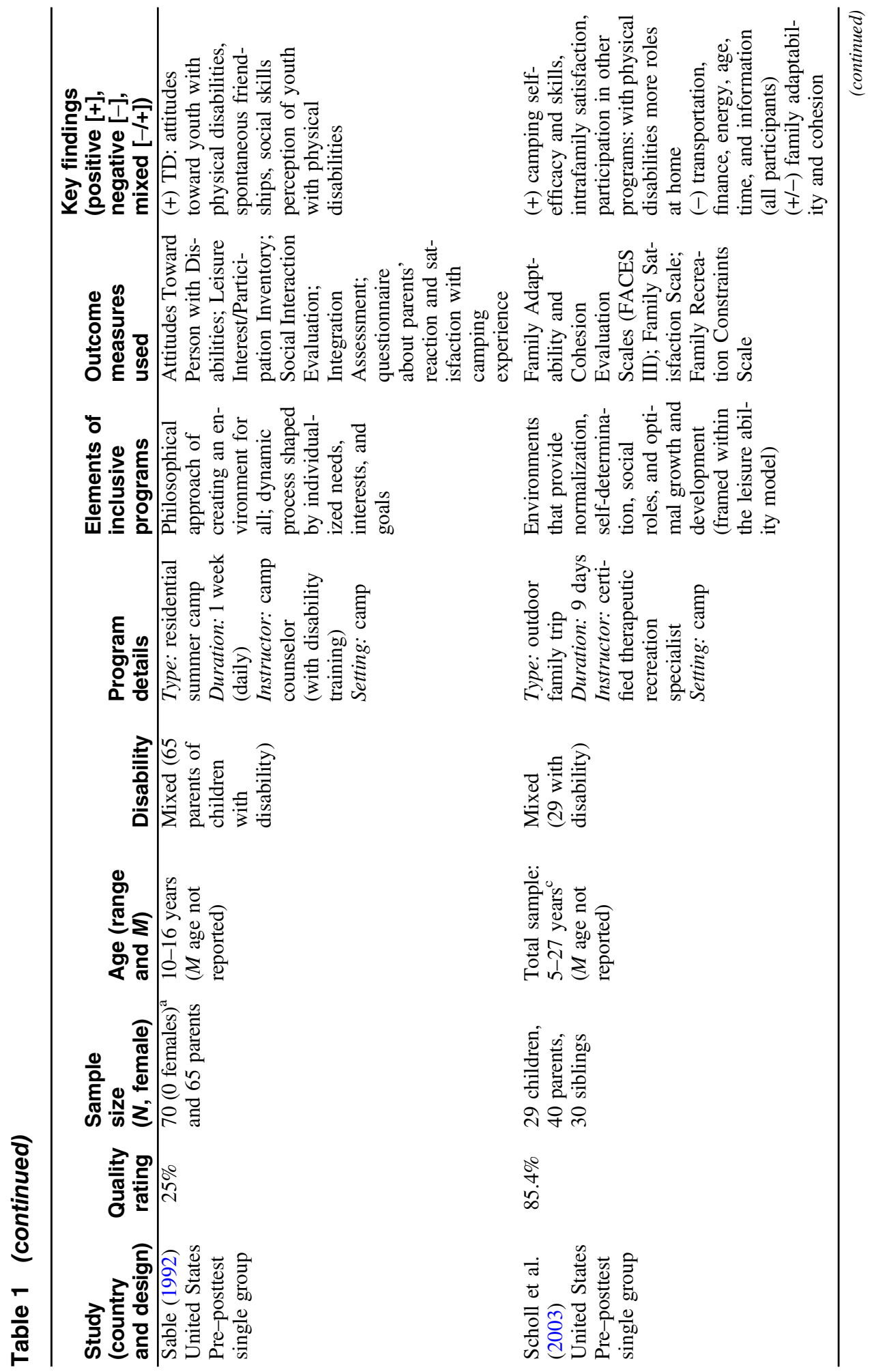




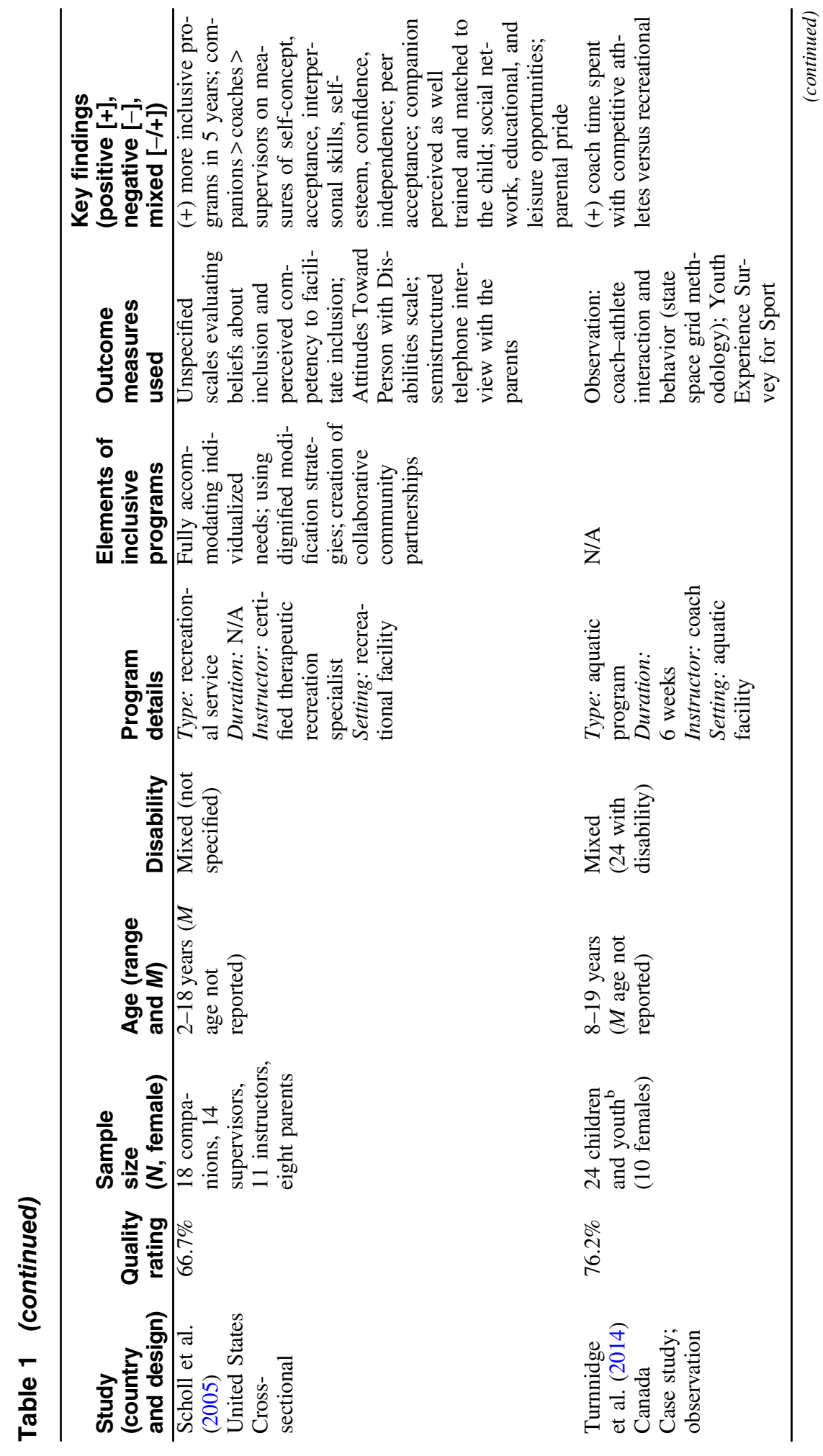




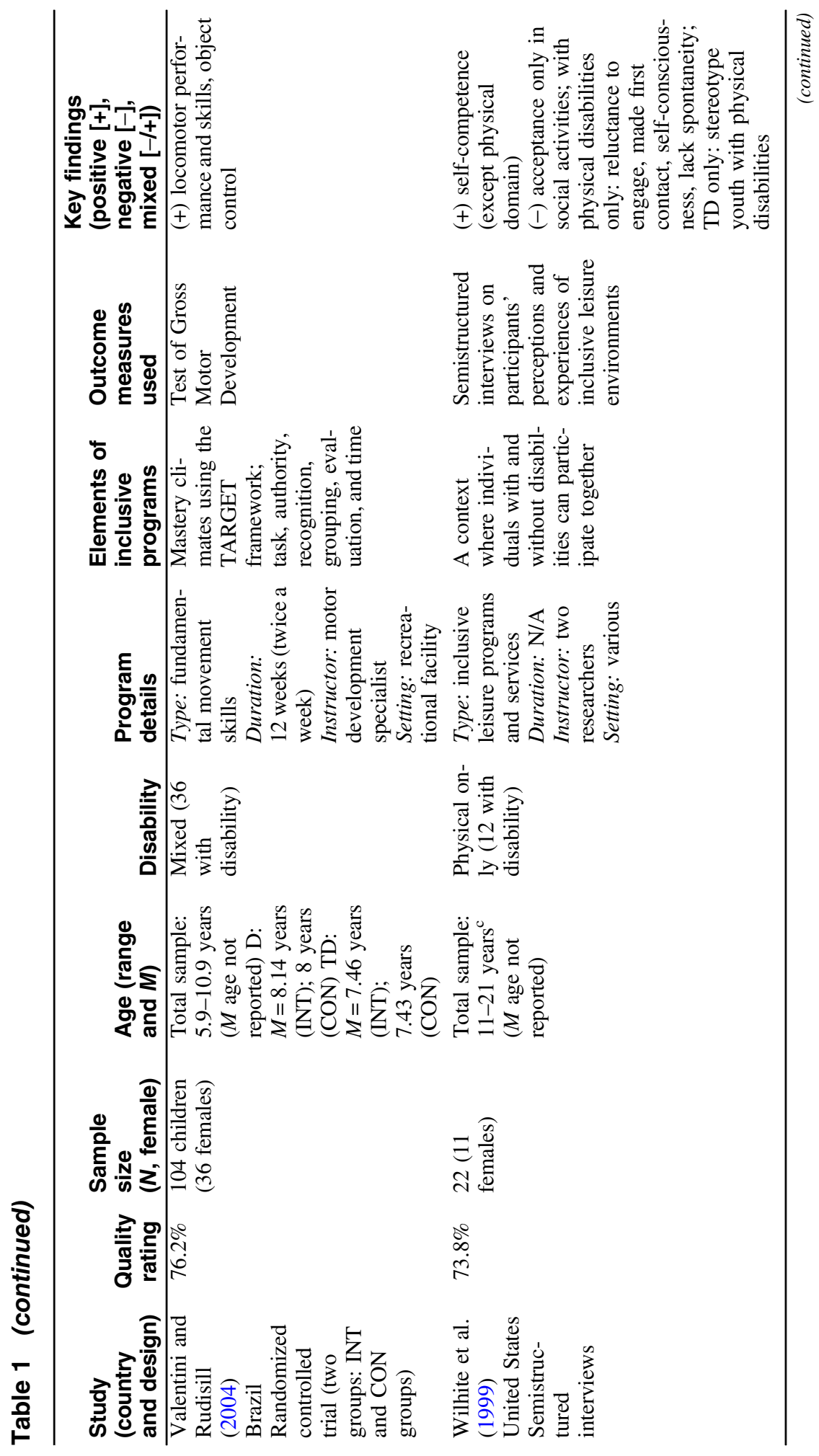




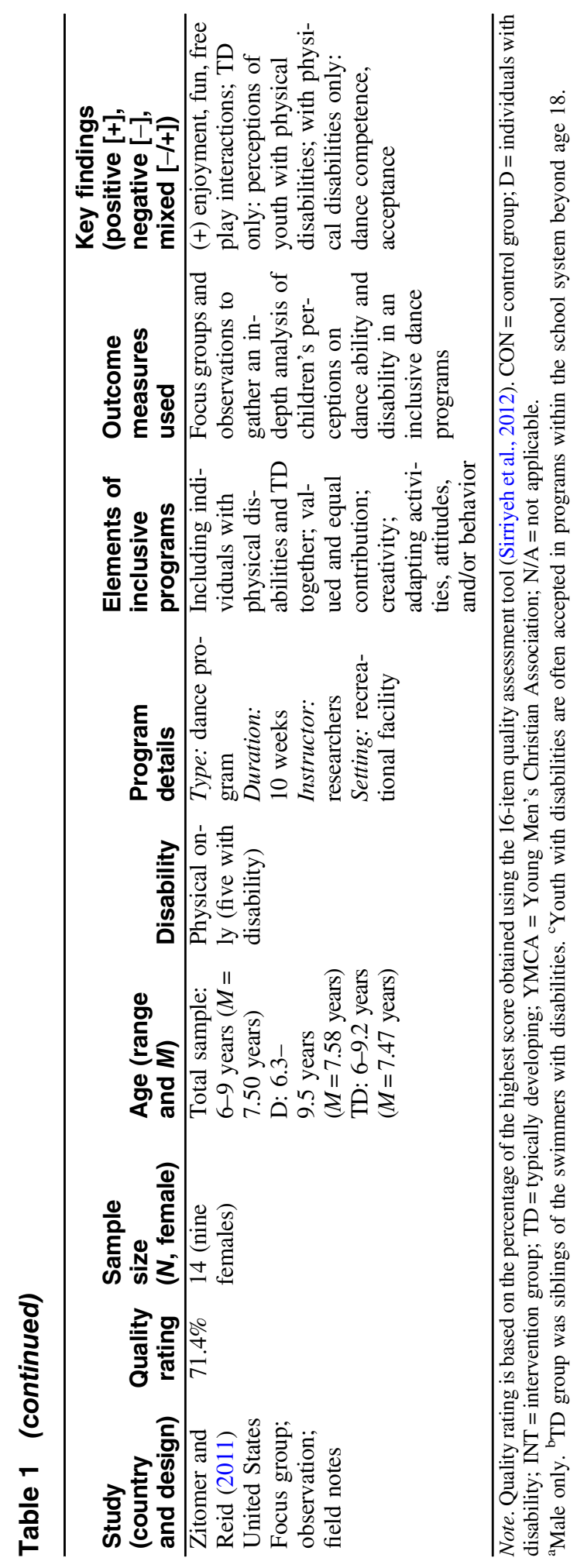


demonstrated good face validity and interrater and test-retest reliability for examining study quality across diverse methodologies (Sirriyeh et al., 2012). Selection of this tool was based on its consideration of additional elements that are often not taken into account in study quality yet are critical to external validity of the study findings. These include application of theoretical frameworks and/or constructs to the research, evidence of user involvement in the study design (e.g., pilot work and consultations with a steering group), and discussion of strengths and limitations. Table 1 summarizes the quality appraisal scores by study methodology.

\section{Best Practice Recommendation Development}

For the summary of the strength of the evidence, the quality ratings were arbitrarily grouped as low $(<60 \%)$, moderate $(60-80 \%)$, or high $(>80 \%)$ to maximize the quality of evidence underlying the best practice recommendations. Results from the studies with ratings that were at least of the moderate methodological quality ( $>60 \%$ total score) informed the best practice recommendations. These recommendations were conceptualized as techniques/strategies that have been successfully demonstrated to achieve the desired outcome. The process used to formulate the best practice recommendations included an initial meeting with all of the authors to discuss the quality appraisal results and to develop a summary of the findings for each outcome, and the development of best practice recommendations for outcomes with sufficient level of evidence by three of the authors (K.A.N., V.G., and K.O.) with further refinement by the remaining authors. Both the summary of the evidence and the refined best practice recommendations were then provided to the international expert panel to review and offer additional revisions based on the evidence and their expertise.

\section{Results}

\section{Identified Studies}

Figure 1 outlines the studies identified at each stage of the search process and reasons for exclusion. A total of 12,887 citations resulted from the initial search, with an additional article included, following consultation with the experts. Upon removal of duplicates, 8,965 potentially eligible articles remained. Citations were screened first by title $(n=8,965)$, then abstract $(n=1,349)$, and, finally, full text $(n=189)$, using the inclusion/exclusion criteria. Of the 189 citations that made it to the full-text screening, 172 citations were removed, resulting in 17 studies that focused on inclusive out-ofschool time PA programs for children/youth with physical disabilities.

Table 1 summarizes the study and program characteristics and main outcomes of the 17 studies included in this review. The next sections describe each of these areas in further detail.

\section{Study Characteristics}

Studies were published between 1986 and 2014, with the majority (81.5\%) since 2000. Most (70.5\%) were conducted in the United States, whereas three were from 
Canada, one from Brazil, and one from the United Kingdom. Nine studies used qualitative methodology (Carter et al., 2014; Devine \& O'Brien, 2007; Devine \& Parr, 2008; Fennick \& Royle, 2003; Jones, 2003; Mayer \& Anderson, 2014; Turnnidge, Côté, Hollenstein, \& Deakin, 2014; Wilhite Devine, \& Goldenberg, 1999; Zitomer \& Reid, 2011), five used quantitative methodology (Biricocchi, Drake, \& Svien, 2014; Hedrick, 1986; Oriel et al., 2012; Sable, 1992; Valentini \& Rudisill, 2004), and three used a mixed-methods research design (Magill-Evans, Darrah, \& Adkins, 2003; Scholl, McAvoy, Rynders, \& Smith, 2003; Scholl, Smith, \& Davison, 2005). Two articles were published using the same dataset (Devine \& O'Brien, 2007; Devine \& Parr, 2008). Overall, quality appraisal ratings of the studies varied from $25 \%$ to $85.4 \%$ (see Table 1), indicating inconsistent study rigor. Lack of clarity on recruitment, intervention, and/or statistical procedures, as well as limited discussion of the study strengths and limitations, typically contributed to low-quality ratings.

\section{Program Participants}

Sample sizes across the 17 studies varied from five to 159 participants. Among the typically developing children and youth, sample sizes varied from four to 71 participants, whereas for those with disabilities, the range was 1-88. Age range of participants was 2-53 years. Four studies included only children (Biricocchi et al., 2014; Carter et al., 2014; Valentini \& Rudisill, 2004; Zitomer \& Reid, 2011), six studies included only youth (Devine \& O'Brien, 2007; Devine \& Parr, 2008; Hedrick, 1986; Magill-Evans et al., 2003; Sable, 1992; Wilhite et al., 1999), four studies included children and youth (Fennick \& Royle, 2003; Oriel et al., 2012; Scholl et al., 2005; Turnnidge et al., 2014), and three studies included children, youth, and adults (Jones, 2003; Mayer \& Anderson, 2014; Scholl et al., 2003). Both genders were represented in all but two of the 17 studies (Biricocchi et al., 2014; Sable, 1992).

With regard to disability, 12 studies involved children and/or youth with physical and intellectual disabilities (Carter et al., 2014; Devine \& O'Brien, 2007; Devine \& Parr, 2008; Fennick \& Royle, 2003; Jones, 2003; Mayer \& Anderson, 2014; Oriel et al., 2012; Sable, 1992; Scholl et al., 2003, 2005; Turnnidge et al., 2014; Valentini \& Rudisill, 2004), and five included children and/or youth with only physical disabilities (Biricocchi et al., 2014; Hedrick, 1986; Magill-Evans et al., 2003; Wilhite et al., 1999; Zitomer \& Reid, 2011). Of the physical disabilities included, cerebral palsy was the most common. Other physical disabilities included muscular dystrophy, visual impairment, spinal cord injury, spina bifida, spinal muscular atrophy, sacral agenesis, brain injury, multiple sclerosis, Noonan syndrome, dwarfism, and a "left arm disability."

\section{Characteristics of Inclusive Out-of-School Time PA Programs}

Settings. Programs were delivered in many settings including recreational centers, aquatics centers, residential summer camps, after-school centers, and sports clubs.

Activity Modes. The activities within these PA programs included dance, swimming, a mix of recreation and swimming, multisports, tennis, fundamental motor 
skills, family-based outdoor skills training, and general recreation activities not otherwise specified. Thirteen studies focused on recreational level programs (Biricocchi et al., 2014; Carter et al., 2014; Devine \& O'Brien, 2007; Devine \& Parr, 2008; Hedrick, 1986; Jones, 2003; Magill-Evans et al., 2003; Oriel et al., 2012; Sable, 1992; Scholl et al., 2003, 2005; Valentini \& Rudisill, 2004; Zitomer \& Reid, 2011), one study was at a competitive level (Wilhite et al., 1999), one study had recreational and competitive participants (Turnnidge et al., 2014), whereas two studies provided no information about the level of the program (Fennick \& Royle, 2003; Mayer \& Anderson, 2014).

Program Duration. Program length varied from 6 days (Devine \& O'Brien, 2007; Devine \& Parr, 2008) to 12 weeks (Valentini \& Rudisill, 2004), although there was no duration specified in six studies (Fennick \& Royle, 2003; Jones, 2003; Magill-Evans et al., 2003; Mayer \& Anderson, 2014; Scholl et al., 2005; Wilhite et al., 1999).

Instructor Expertise. Rehabilitation staff (i.e., certified therapeutic recreation specialists and physiotherapists) were the most common program leaders. Other individuals who served as instructors included: researchers in kinesiology and recreation/leisure studies, camp counselors, motor development specialists with an extensive teaching background, high-performance coaches with disability-specific training, athletes/para-athletes, and undergraduate education and health science student coaches. Six studies had no information about instructors (Carter et al., 2014; Devine \& O'Brien, 2007; Devine \& Parr, 2008; Jones, 2003; Magill-Evans et al., 2003; Mayer \& Anderson, 2014).

Program/Activity Modifications. A variety of modifications were made to the programs including (a) low-technology adaptations to provide additional support and stability (Devine \& O'Brien, 2007; Devine \& Parr, 2008); (b) availability of additional equipment, such as pool flotation devices (Oriel et al., 2012), specialized sport wheelchairs (Hedrick, 1986), modified archery bows (Sable, 1992) and/or other adapted recreational equipment (Biricocchi et al., 2014; Devine \& O'Brien, 2007; Devine \& Parr, 2008; Hedrick, 1986; Oriel et al., 2012); (c) altering the physical (Sable, 1992) and/or social (e.g., the presence of more staff or peer mentors; Biricocchi et al., 2014; Devine \& O'Brien, 2007; Devine \& Parr, 2008; Sable, 1992; Wilhite et al., 1999; Zitomer \& Reid, 2011) environments to provide more tangible support for participants to execute the activities; and (d) enhancing the delivery methods of the instructions through pictures and/or additional written text (Valentini \& Rudisill, 2004). Partner and small-group strategies were also implemented (Carter et al., 2014; Devine \& O'Brien, 2007; Devine \& Parr, 2008; Oriel et al., 2012). Two programs provided one-on-one support from an instructor (Fennick \& Royle, 2003; Sable, 1992). In several cases, accommodations were specifically noted to be minimal and naturally occurring to avoid undue attention and to maintain the integrity of the activity while simultaneously increasing participants' awareness of the wide range of abilities within the group (Jones, 2003; Scholl et al., 2005).

Operationalization of Inclusion. An additional component extracted from the studies, when available, was the characteristic(s) used to describe inclusive out-ofschool time PA programs. Table 1 provides a brief description of the key 
characteristics identified in 13 of the 17 studies. A minimum criterion to be included in this review was that children/youth with and without physical disabilities must have engaged in the program together. Other concepts applied in several studies were (a) inclusion being a dynamic process involving valued and equal participation from all (Devine \& O'Brien, 2007; Devine \& Parr, 2008; Mayer \& Anderson, 2014; Zitomer \& Reid, 2011); (b) mutual respect (Devine \& O'Brien, 2007; Devine \& Parr, 2008); (c) celebration of differences (Devine \& O'Brien, 2007; Devine \& Parr, 2008); (d) adapting activities on an "as needed basis" (Devine \& O'Brien, 2007; Devine \& Parr, 2008; Mayer \& Anderson, 2014; Zitomer \& Reid, 2011); (e) enhancing opportunities for mastery experiences and autonomy (Valentini \& Rudisill, 2004); (f) considering the impact of the physical and social environment (Magill-Evans et al., 2003; Mayer \& Anderson, 2014; Zitomer \& Reid, 2011); and (g) facilitating individualization, learning, social acceptance, and creativity (Oriel et al., 2012; Valentini \& Rudisill, 2004; Zitomer \& Reid, 2011).

\section{Study Outcomes}

Table 1 summarizes the main outcomes of each study. Below is a summary of the evidence for each of the four categories of impact of the programs, followed by a formulation of recommended best practices to achieve that outcome, based upon results of studies of at least the moderate methodological quality ( $>60 \%$ total rating score). A summary of these best practice recommendations is provided in Table 2.

Social Skills and Relationships. Twelve studies evaluated the effect of inclusive out-of-school time PA programs on social skills and the relationships between children and youth with physical disabilities and their typically developing peers (Biricocchi et al., 2014; Carter et al., 2014; Devine \& O'Brien, 2007; Devine \& Parr, 2008; Hedrick, 1986; Jones, 2003; Mayer \& Anderson, 2014; Oriel et al., 2012; Sable, 1992; Scholl et al., 2005; Wilhite et al., 1999; Zitomer \& Reid, 2011), along with their family (Biricocchi et al., 2014; Jones, 2003; Mayer \& Anderson, 2014; Scholl et al., 2003, 2005), and/or instructors (Devine \& O'Brien, 2007; Devine \& Parr, 2008; Jones, 2003; Magill-Evans et al., 2003; Scholl et al., 2005; Zitomer \& Reid, 2011). Of these 12 studies, eight were rated as moderate to high quality (Devine \& O'Brien, 2007; Devine \& Parr, 2008; Hedrick, 1986; Mayer \& Anderson, 2014; Scholl et al., 2005; Wilhite et al., 1999; Zitomer \& Reid, 2011), whereas the remaining four (Biricocchi et al., 2014; Carter et al., 2014; Jones, 2003; Sable, 1992) were rated as low quality.

Inclusive out-of-school time PA programs provided an opportunity to enhance social interactions between children and youth with physical disabilities and their typically developing peers (Biricocchi et al., 2014; Carter et al., 2014; Devine \& O’Brien, 2007; Devine \& Parr, 2008; Mayer \& Anderson, 2014; Sable, 1992; Scholl et al., 2005; Zitomer \& Reid, 2011). Although these peer interactions were not always easy to initiate, they were valued by those with physical disabilities (Devine \& O'Brien, 2007). Acceptance for children and youth in the program was enhanced in two studies (Mayer \& Anderson, 2014; Scholl et al., 2005). However, peer relationships within some of the programs may have been superficial, as typically developing youth and youth with physical disabilities reported having 


\section{Table 2 Summary of the Best Practice Recommendations for Inclusive Out-of-School Time Physical Activity (PA) Programs}

\begin{tabular}{|c|c|c|}
\hline Outcome & Best practice recommendations & $\begin{array}{l}\text { Supporting } \\
\text { evidence }\end{array}$ \\
\hline $\begin{array}{l}\text { Social skills and } \\
\text { relationships }\end{array}$ & $\begin{array}{l}\text { - Equal and valued status can be promoted } \\
\text { through group decision making and } \\
\text { assigning group members with specific } \\
\text { roles and responsibilities. } \\
\text { - Strategies to foster social skills and } \\
\text { relationships include (a) focusing on } \\
\text { common goals and interests within the } \\
\text { group; (b) lessening the focus on } \\
\text { competition and more toward creating } \\
\text { mastery (task-oriented) climates; and } \\
\text { (c) including cooperative activities to } \\
\text { encourage positive social interactions } \\
\text { between all program participants. } \\
\text { - Praising behaviors that undermine the } \\
\text { abilities of participants with disabilities } \\
\text { (e.g., having participants act as "helpers" } \\
\text { to push a child's wheelchair) should be } \\
\text { replaced with structuring formal contact } \\
\text { experiences for participants to get to } \\
\text { know one another and learn about each } \\
\text { other's strengths as a chance to see past } \\
\text { the impairment, so that reciprocal } \\
\text { relationship development is possible. }\end{array}$ & $\begin{array}{l}\text { Devine and O'Brien } \\
\text { (2007); Devine and } \\
\text { Parr (2008); Valentini } \\
\text { and Rudisill (2004); } \\
\text { Zitomer and Reid } \\
\text { (2011) }\end{array}$ \\
\hline $\begin{array}{l}\text { Physical skill } \\
\text { development }\end{array}$ & $\begin{array}{l}\text { - Focus on the development and refinement } \\
\text { of fundamental movement skills through } \\
\text { the use of mastery-oriented, } \\
\text { individualized instructional styles that } \\
\text { allow for choice. } \\
\text { - Instructors should be attentive toward } \\
\text { providing developmentally appropriate } \\
\text { yet challenging activities to enhance } \\
\text { participants' mastery skills. }\end{array}$ & $\begin{array}{l}\text { Hedrick (1986); } \\
\text { Valentini and Rudisill } \\
\text { (2004); Scholl et al. } \\
\text { (2003); Zitomer and } \\
\text { Reid (2011) }\end{array}$ \\
\hline $\begin{array}{l}\text { Psychological } \\
\text { well-being }\end{array}$ & - Insufficient evidence & \\
\hline PA participation & - Insufficient evidence & \\
\hline
\end{tabular}

$\overline{\text { Note. Studies with ratings that were at least of the moderate methodological quality ( } \geq 60 \% \text { total score) }}$ informed the best practice recommendations. These recommendations were conceptualized as techniques or strategies that have been successfully demonstrated to achieve the desired outcome.

different interests (Devine \& O'Brien, 2007). In some cases, typically developing youth considered themselves to be more like program "helpers" than friends with those with physical disabilities, whereas youth with physical disabilities were more likely to perceive a reciprocal relationship (Devine \& O'Brien, 2007; Devine \& Parr, 2008). In one study (Oriel et al., 2012), youth with physical disabilities did not feel comfortable playing with their typically developing peers. This finding is 
consistent with the lack of focus on friendship-building components within some out-of-school time PA programs (Jones, 2003), and with youth with physical disabilities having to often initiate first contact with their peers (Wilhite et al., 1999).

There was evidence to support increased disability awareness among typically developing youth who took part in inclusive out-of-school time PA programs (Carter et al., 2014; Hedrick, 1986; Mayer \& Anderson, 2014; Sable, 1992), especially in relation to physical and social skills. Although increases in positive and decreases in negative attitudes were noted among typically developing youth toward their peers with physical disabilities (Sable, 1992), one study found typically developing children continued to define differences between themselves and their peers with physical disabilities, based on the additional equipment that the children with a physical disability may require (e.g., wheelchairs and walkers; Zitomer \& Reid, 2011).

Several studies demonstrated an association between inclusive out-of-school time PA programs and improvements in social skills and reductions in social stigma (Carter et al., 2014; Jones, 2003; Sable, 1992). For example, following a 7-day residential camp, typically developing youth perceived their peers with physical disabilities to be capable of "normal" social interactions (Sable, 1992). However, deficits in social skills among some youth with physical disabilities may limit their opportunity to join inclusive out-of-school time PA programs (Jones, 2003) and may increase self-consciousness, thus limiting social interactions (Wilhite et al., 1999). Inclusive out-of-school time PA programs may highlight the sport skill differences between youth with and without physical disabilities; however, these programs may be a way to improve these skills (Jones, 2003).

The role of instructors in facilitating social interactions among program participants was supported in many studies (Carter et al., 2014; Devine \& Parr, 2008; Jones, 2003; Magill-Evans et al., 2003; Scholl et al., 2005; Zitomer \& Reid, 2011). Well-trained instructors were capable of adapting the physical activities (Scholl et al., 2005) and would often serve as role models of appropriate social behaviors within the group, which facilitated friendships and positive interactions between youth with and without physical disabilities (Devine \& O'Brien, 2007; Devine \& Parr, 2008). Using the principles of contact theory (Allport, 1954), instructors promoted equal status within the group by focusing on common goals and interests, lessening the emphasis on competition and enhancing enjoyment among the group (Devine \& Parr, 2008; Zitomer \& Reid, 2011). One study concluded that instructors who praised typically developing youth for physically assisting their peers with physical disabilities, such as by pushing their wheelchair, enhanced group differences, thus promoting negative (hierarchy-based) social interactions (Devine \& O'Brien, 2007). In some cases, instructors' lack of disability awareness and inability to modify activities were a concern among parents of children and youth with physical disabilities (Jones, 2003; Magill-Evans et al., 2003).

Evidence also supported the positive impact inclusive out-of-school time PA programs have on familial interactions for children and youth with physical disabilities (Biricocchi et al., 2014; Scholl et al., 2003, 2005). In particular, increased parental pride and family social networks (Scholl et al., 2005), 
satisfaction with family roles and participation in leisure activities (Scholl et al., 2003), and increased independence were shown for those with a physical disability, both within and outside of programs (Biricocchi et al., 2014; Scholl et al., 2003).

The best practices for enhancing social skills and relationships supported from the evidence are described as follows. Social engagement, peer acceptance, and friendship are at the core of successful inclusive out-of-school time PA programs, above and beyond the benefits of the development of physical skills and participation in PA. Equal and valued status can be promoted through group decision making and assigning group members with specific roles and responsibilities (Devine \& O'Brien, 2007; Devine \& Parr, 2008). Strategies that can be incorporated into out-of-school PA time programs to foster social skills and relationships included (a) focusing on common goals and interests within the group (Devine \& O'Brien, 2007; Devine \& Parr, 2008); (b) lessening the focus on competition and more toward creating mastery (task-oriented) climates (Valentini \& Rudisill, 2004); and (c) including cooperative activities to encourage positive social interactions between all program participants (e.g., Devine \& O'Brien, 2007, Zitomer \& Reid, 2011). Praising behaviors that undermine the abilities of participants with disabilities (e.g., having participants act as "helpers" to push a child's wheelchair; Devine \& O'Brien, 2007) should be replaced with structuring formal contact experiences for participants to get to know one another and learn about each other's strengths as a chance to see past the impairment, so that reciprocal relationship development is possible.

Physical Skill Development. Skill development in the physical domain was examined in 11 of the 17 included studies. Six studies were of moderate to high quality (Hedrick, 1986; Mayer \& Anderson, 2014; Scholl et al., 2003; Valentini \& Rudisill, 2004; Wilhite et al., 1999; Zitomer \& Reid, 2011), and five were rated as low quality (Biricocchi et al., 2014; Carter et al., 2014; Fennick \& Royle, 2003; Jones, 2003; Sable, 1992).

The following changes in physical skills were reported among all participants following program completion: improvements in locomotion (Biricocchi et al., 2014; Valentini \& Rudisill, 2004), object control (Valentini \& Rudisill, 2004), and activity-specific skills (Carter et al., 2014; Hedrick, 1986; Scholl et al., 2003; Zitomer \& Reid, 2011). A randomized controlled trial (Valentini \& Rudisill, 2004) evaluated an inclusive mastery-focused climate in which the instructor used an individualized instructional approach (i.e., the TARGET framework) to enhance autonomy and competence in a challenging manner by providing tasks that were specific to the individuals' interests, contained varying levels of challenge, and that were self-paced and fostered recognition of personal efforts and achievements through individualized goal setting and feedback (Valentini \& Rudisill, 2004). They concluded that attention of the instructors should be directed toward providing developmentally appropriate yet challenging activities to enhance participants' mastery skills, as well as promoting shared and offering choice. This mastery-climate intervention resulted in greater improvements in locomotor and object control than a free-play comparison condition, regardless of the presence of a physical disability. In a cross-sectional study, long-term improvements in physical (outdoor) skills were also reported among youth with physical 
disabilities (via parent report) in an inclusive camping program (Scholl et al., 2003). These skills transferred to other physical tasks, such as performing household chores. Two studies highlighted a concern among parents with the (in)ability of inclusive out-of-school time PA programs, in comparison with segregated programs, to provide appropriate, progressive skill-based challenges for their child with physical disabilities (Jones, 2003; Mayer \& Anderson, 2014).

The best practices for enhancing physical skill development supported from the evidence are described as follows. Fundamental movement skills, such as object control and locomotion, are critical components for physical literacy (Tremblay \& Lloyd, 2010; Watkinson \& Mulion, 1988). Inclusive out-of-school time PA programs must be built with the focus on the development and refinement of such fundamental movement skills through the use of mastery-oriented, individualized instructional styles (e.g., Valentini \& Rudisill, 2004) that allow for choice. Instructors should be attentive toward providing developmentally appropriate yet challenging activities to enhance participants' mastery skills.

Psychological Well-Being. Nine of the 17 studies examined the impact of inclusive out-of-school time PA programs on psychological well-being. Seven were of moderate to high quality (Mayer \& Anderson, 2014; Oriel et al., 2012; Scholl et al., 2003, 2005; Turnnidge et al., 2014; Wilhite et al., 1999; Zitomer \& Reid, 2011) whereas two were of low quality (Carter et al., 2014; Fennick \& Royle, 2003).

Eight studies reported on the psychological benefits of inclusive out-of-school time PA programming provided to all participants (Mayer \& Anderson, 2014; Scholl et al., 2003, 2005; Turnnidge et al., 2014; Wilhite et al., 1999; Zitomer \& Reid, 2011), particularly in the form of self-perceptions (e.g., self-efficacy, autonomy, self-concept, and self-esteem). Three studies reported on participants' enjoyment of the programs (Carter et al., 2014; Fennick \& Royle, 2003; Zitomer \& Reid, 2011), whereas one study (Oriel et al., 2012) reported a decrease in general happiness among children and youth with physical disabilities in an aquatics program. As concluded by the authors, greater self-reflection and awareness of functional limitations and overall participation restrictions were possible explanations for this decrease in happiness.

The available studies examining the benefits of psychological well-being in inclusive out-of-school time PA programs do not provide enough evidence to recommend any particular best practices to successfully enhance psychological well-being within these programs.

Participation in PA. None of the 17 studies explicitly evaluated extent of the children or youths' PA participation within or outside of the program (e.g., attendance frequency, duration, and intensity of PA behavior). However, six studies examined personal and environmental contextual factors of PA participation, such as enjoyment, staff training, and support (Fennick \& Royle, 2003; Jones, 2003; Magill-Evans et al., 2003; Scholl et al., 2005; Wilhite et al., 1999; Zitomer \& Reid, 2011). In one study (Mayer \& Anderson, 2014), parents encouraged their child's enrolment in PA programs based on their personal beliefs of what was best for their child (e.g., perceived physical ability and program appropriateness).

No evidence is available from these studies to recommend best practices to successfully enhance PA participation of children and youth in inclusive out-ofschool time PA programs. 


\section{Discussion}

This scoping review comprehensively examined the empirical evidence related to inclusive out-of-school time PA programs for children and youth with physical disabilities. Based on the available evidence, best practice recommendations were provided for enhancing social skills and relationships and physical skill development. These recommendations are consistent with Emes, Longmuir, and Downs' (2000) abilities-based approach in adapted PA where the focus is on using a person-centered approach to increase the compatibility between the demands of an activity with the interests, capabilities, and abilities of an individual. The following section discusses the implications of this review and future directions in the area of inclusive out-of-school time PA.

Participation in out-of-school time settings is a widespread concern in pediatric disability (Imms et al., 2016). However, none of the studies in this review explicitly evaluated the PA participation levels of the program participants. This is contrary to the existing literature on out-of-school PA programs where improvements in PA participation have been documented among typically developing children and youth (e.g., Beets, Wallner, \& Beighle, 2010, Pate \& O'Neill, 2009). Attendance and involvement have recently been identified as two consistent elements of participation for children with disabilities (Imms et al., 2016). These two constructs capture both the objective and subjective experiences of engaging in an activity (Imms et al., 2016). Future research that incorporates both of these experiences from multiple sources, such as the program staff, the children and youth enrolled in the programs, and their parents/guardians, is warranted.

In addition to improvements in PA participation, out-of-school programs have been shown to have positive effects on physical health (Beets et al., 2010; Messiah et al., 2015), fitness (Beets et al., 2010; London \& Gurantz, 2013), and positive development (Coatsworth \& Conroy, 2007; Vandell, Pierce, \& Dadisman, 2005) among typically developing children and youth. Findings from this review add to the existing literature on out-of-school time PA programs by demonstrating the positive impact inclusive programs can have on the psychosocial health and physical competence of both typically developing children and youth and those with physical disabilities. Given the underrepresentation of children and youth with disabilities in out-of-school time programs (Law et al., 2006; Wiley \& Niedzielski-Eichner, 2017), particularly those with more severe types of disabilities (Kleinert, Miracle, \& Sheppard-Jones, 2007), this review fills a critical gap in the out-of-school time literature.

Limited evidence was available to support specific recommendations for two of the outcomes associated with inclusive out-of-school time PA programs, psychological well-being and PA participation. A possible future research direction is for researchers and both community programmers and individuals who experience disability to collaborate to gather more detailed data on the different strategies that are implemented by instructors within inclusive out-of-school time PA settings, and to examine their influence on the psychological well-being of the program participants. Such strategies may include offering activity choices, selfselected pacing of the execution of the activities in a particular session, or having the opportunity to work with the same instructor over subsequent program registrations. This type of rigorous "mapping" of strategies can then be used to 
examine what settings, at what age, and during what types of activities inclusive out-of-school time PA programs can successfully enhance psychological wellbeing outcomes.

An overarching theme emerging across the four outcomes is the training of the instructors delivering inclusive out-of-school time PA programs. Instructor training was highlighted in all 17 studies as a critical component of the successful implementation of inclusive out-of-school time PA programs. This was voiced by many parents of the children and youth with physical disabilities. Further work and research are needed on the development and evaluation of training resources for staff to effectively deliver inclusive PA programs for children and youth with a wide range of abilities. Such resources need to focus on training related to personal factors (e.g., common physical disabilities and co-occurring conditions), as well as the management of imposed environmental (e.g., equipment availability, placement, or usage) and financial barriers (e.g., fee structures). By doing so, instructors are more likely to provide safe, positive, and motivating environments for all children and youth to participate in a meaningful way (Goodwin, 2003).

An additional gap identified in this review was the lack of clarity in how the term "inclusion" has been applied to out-of-school time PA settings. Thirteen of the 17 studies provided a range of characteristics and/or conceptual frameworks (e.g., contact theory) that were central to the PA program(s) of interest. Consequently, some of the studies that were included in this review were not truly inclusive outof-school time PA programs (e.g., recreation therapists ran the program rather than typical community out-of-school time staff and volunteers). Rather than excluding these programs from the review, our research team felt the lack of true inclusivity, despite what the programs are purported to be, was an important issue to highlight. This inconsistent operationalization of inclusion is a concern that has been previously raised in the field of adapted physical education (e.g., Harvey, 2013), and, more generally, recreation and leisure (e.g., Hall, Dunlap, CaustonTheoharis, \& Theoharis, 2013). For the field of adapted PA to continue to move forward in this area of research, there is a need for greater transparency in the ways in which aspects of inclusion that have been identified as critical to adapted PA (e.g., meaningful participation, belongingness, autonomy, and social connectedness; DePauw \& Doll-Tepper, 2000; Goodwin, 2003; Martin \& Mushett, 1996) were considered in the design and delivery of out-of-school time PA programs.

There are several limitations of the review that must be highlighted. First, this review only focused on published studies and therefore did not include any gray literature. Hence, our findings may not provide a full map of the literature on inclusive out-of-school time PA programs (Arksey \& O'Malley, 2005; Levac et al., 2010). Second, the heterogeneity of studies included in this review, both with respect to methodologies and the settings in which the programs occurred, presented a challenge when informing our best practice recommendations from the evidence. The quality appraisal ratings were one strategy that was used to maximize the quality of evidence underlying the best practice recommendations, along with including an international expert panel into the various stages of the scoping review process. The minimal evidence available for some of the outcomes identified meant that our research team and expert panel were not confident in providing the best practice recommendations where evidence did not exist to 
support such claims. More rigorous methodological designs are warranted, particularly in the areas of psychological well-being and PA participation, to further understand the impact inclusive PA programs have on children and youth with a wide range of abilities. Third, the findings and the best practice recommendations are limited primarily to children and youth with mild-to-moderate physical disabilities. Few of the studies included in this review focused on children and youth with more severe types of physical disabilities, a marginalized group within out-of-school time settings (Kleinert et al., 2007). Exploring ways to include the voices of children and youth with more complex needs within inclusive PA settings is warranted.

\section{Acknowledgments}

We would like to recognize our international expert panel (Janke de Groot, Donna Goodwin, Meghann Lloyd, Carol Maher, Roxanne Seaman, Nora Shields, and Kerri Vanderbom) for their contribution to this review. We would also like to thank for Pui Wong her guidance and expertise with the literature search, as well as Alicia Luciani for her assistance with the study screening process. This project was funded through the Social Sciences and Humanities Research Council of Canada's (SSHRC) Insight Development Grant.

\section{References}

Allport, G.W. (1954). The nature of prejudice. New York, NY: Addison-Wesley.

Arksey, H., \& O’Malley, L. (2005). Scoping studies: Towards a methodological framework. International Journal of Social Research Methodology, 8(1), 19-32. doi:10.1080/ 1364557032000119616

Beets, M.W., Beighle, A., Erwin, H.E., \& Huberty, J.L (2009). After-school program impact on physical activity and fitness: A meta-analysis. American Journal of Preventive Medicine, 36(6), 527-537.

Beets, M.W., Wallner, M., \& Beighle, A. (2010). Defining standards and policies for promoting physical activity in afterschool programs. Journal of School Health, 80(8), 411-417. PubMed doi:10.1111/j.1746-1561.2010.00521.x

Biricocchi, C., Drake, J., \& Svien, L. (2014). Balance outcomes following a tap dance program for a child with congenital myotonic muscular dystrophy. Pediatric Physical Therapy 26(3), 360-365. PubMed doi:10.1097/PEP.0000000000000064

Block, M.E., \& Malloy, M. (1998). Attitudes on inclusion of a player with disabilities in a regular softball league. Mental Retardation, 36(2), 137-144. PubMed doi:10.1352/ 0047-6765(1998)036<0137:AOIOAP >2.0.CO;2

Block, M.E., \& Obrusnikova, I. (2007). Inclusion in physical education: A review of the literature from 1995-2005. Adapted Physical Activity Quarterly, 24(2), 103-124. PubMed doi:10.1123/apaq.24.2.103

Carter, B., Grey, J., McWilliams, E., Clair, Z., Blake, K., \& Byatt, R. (2014). 'Just kids playing sport (in a chair)': Experiences of children, families and stakeholders attending a wheelchair sports club. Disability \& Society, 29(6), 938-952. doi:10.1080/09687599. 2014.880329

Castenada, L., \& Sherril, C. (1999). Family participation in challenger baseball: Critical theory perspectives. Adapted Physical Activity Quarterly, 16(4), 372-388. doi:10. 1123/apaq.16.4.372

Coatsworth, J.D., \& Conroy, D.E. (2007). Youth sport as a component of organized afterschool programs. New Directions for Youth Development, 115, 57-74. PubMed doi: $10.1002 / \mathrm{yd} .223$ 
Costin, S.E., \& Jones, D.C. (1992). Friendship as a facilitator of emotional responsiveness and prosocial interventions among young children. Developmental Psychology, 28(5), 941-947. doi:10.1037/0012-1649.28.5.941

DePauw, K.P., \& Doll-Tepper, G. (2000). Toward progressive inclusion and acceptance: Myth or reality? The inclusion debate and bandwagon discourse. Adapted Physical Activity Quarterly, 17(2), 135-143. doi:10.1123/apaq.17.2.135

Devine, M.A., \& O'Brien, M.B. (2007). The mixed bag of inclusion: An examination of an inclusive camp using contact theory. Therapeutic Recreation Journal, 41(3), 201-222.

Devine, M.A., \& Parr, M.G. (2008). "Come on in, but not too far": Social capital in an inclusive leisure setting. Leisure Sciences, 30(5), 391-408. doi:10.1080/ 01490400802353083

Duncan, S.C., Duncan, T.E., \& Strycker, L.A. (2005). Sources and types of social support in youth physical activity. Health Psychology, 24(1), 3-10. PubMed doi:10.1037/02786133.24.1.3

Dzewaltowski, D.A. (2008). Community out-of-school physical activity promotion. In A.L. Smith \& S.J.H. Biddle (Eds.), Youth physical activity and inactivity: Challenges and solutions (pp. 377-401). Champaign, IL: Human Kinetics.

Emes, C., Longmuir, P., \& Downs, P. (2000). An abilities-based approach to service delivery and professional preparation in adapted physical activity. Adapted Physical Activity Quarterly, 19(4), 403-419. doi:10.1123/apaq.19.4.403

Fennick, E., \& Royle, J. (2003). Community inclusion for children and youth with developmental disabilities. Focus on Autism and Other Developmental Disabilities, 18(1), 20-27. doi:10.1177/108835760301800104

Glegg, S.M.N., Tatla, S.K., \& Holsti, L. (2014). The GestureTek virtual reality system in rehabilitation: A scoping review. Disability and Rehabilitation Assistive Technology, 9(2), 89-111. PubMed doi:10.3109/17483107.2013.799236

Goodwin, D.L. (2001). The meaning of help in PE: Perceptions of students with physical disabilities. Adapted Physical Activity Quarterly, 18(3), 289-303. doi:10.1123/apaq. 18.3.289

Goodwin, D.L. (2003). Inclusive physical education. In R.D. Steadward, G.D. Wheeler, \& E.J. Watkinson (Eds.), Adapted Physical Activity (pp. 189-208). Edmonton, AB: The University Press.

Grenier, M.A. (2011). Coteaching in physical education: A strategy for inclusive practice. Adapted Physical Activity Quarterly, 28(2), 95-112. PubMed doi:10.1123/apaq.28. 2.95

Hall, A., Dunlap, T., Causton-Theoharis, J., \& Theoharis, G. (2013). The power of inclusive camp experience. Camping Magazine, 86(1), 60-65.

Harvey, W. (2013). Adapted and inclusive health and physical education. In D.B. Robinson \& L. Randall (Eds.), Teaching physical education today: Canadian perspectives (pp. 137-152). Toronto, Canada: Thompson Educational Publishing.

Hedrick, B.N. (1986). Wheelchair sport as a mechanism for altering the perceptions of the nondisabled regarding their disabled peers' competence. Therapeutic Recreation Journal, 20(4), 72-84.

Imms, C., Adair, B., Keen, D., Ullenhag, A., Rosenbaum, P., \& Granlund, M. (2016). 'Participation': A systematic review of language, definitions, and constructs used in intervention research with children with disabilities. Developmental Medicine \& Child Neurology, 58(1), 29-38. PubMed doi:10.1111/dmcn.12932

International Physical Literacy Association. (2016). International Physical Literacy Association homepage. Plymouth, UK: International Physical Literacy Association. Retrieved from http://www.physical-literacy.org.uk

Jones, D.B. (2003). "Denied from a lot of places" barriers to participation in community recreation programs encountered by children with disabilities in Maine: Perspectives of 
parents. Leisure/Loisir: Journal of the Canadian Association for Leisure Studies, 28(1/2), 49-69. doi:10.1080/14927713.2003.9649939

Kalyavas, V., \& Reid, G. (2003). Sport adaptation, participation, and enjoyment of students with and without physical disabilities. Adapted Physical Activity Quarterly, 20(2), 182-199. doi:10.1123/apaq.20.2.182

Kastner, M., Tricco, A.C., Soobiah, C., Lillie, E., Perrier, L., Horsley, T., . . Straus, S.E. (2012). What is the most appropriate knowledge synthesis method to conduct a review? Protocol for a scoping review. BMC Medical Research Methodology, 12(1), 114. PubMed doi:10.1186/1471-2288-12-114

Kleinert, H.L., Miracle, S.A., \& Sheppard-Jones, K. (2007). Including students with moderate and severe disabilities in extracurricular and community recreation activities. Teaching Exceptional Children, 39(6), 33-38. doi:10.1177/004005990703900605

Law, M., King, G., King, S., Kertoy, M., Hurley, P., Rosenbaum, P., . . Hanna, S. (2006). Pattern of participation in recreational and leisure activities among children with complex physical disabilities. Developmental Medicine \& Child Neurology, 48(5), 337-342. PubMed doi:10.1017/S0012162206000740

Levac, D., Colquhoun, H., \& O'Brien, K.K. (2010). Scoping studies: Advancing the methodology. Implementation Science, 5(1), 69. PubMed doi:10.1186/1748-5908-5-69

London, R.A., \& Gurantz, O. (2013). Afterschool program participation, youth physical fitness, and overweight. American Journal of Preventive Medicine, 44(3), S200-S207. PubMed doi:10.1016/j.amepre.2012.11.009

Magill-Evans, J., Darrah, J., \& Adkins, R. (2003). Youths with cerebral palsy and their satisfaction with recreational services: Implications for inclusion. Leisure/Loisir: Journal of the Canadian Association for Leisure Studies, 28(1/2), 71-86. doi:10. 1080/14927713.2003.9649940

Martin, J. (2010). The psychosocial dynamics of youth disability sport. Sport Science Review, 19(5-6), 49-70.

Martin, J.J., \& Mushett, C. (1996). Social support mechanisms among athletes with disabilities. Adapted Physical Activity Quarterly, 13(1), 74-83. doi:10.1123/apaq. 13.1.74

Mayer, W.E., \& Anderson, L.S. (2014). Perceptions of people with disabilities and their families about segregated and inclusive recreation involvement. Therapeutic Recreation Journal, 48(2), 150-168.

Messiah, S.E., Diego, A., Kardys, J., Kirwin, K., Hanson, E., Nottage, R., . . A Arheart, K.L. (2015). Effect of a park-based after-school program on participant obesity-related health outcomes. American Journal of Health Promotion, 29(4), 217-225. PubMed doi:10.4278/ajhp.120705-QUAN-327

Obrusnikova, I., Block, M.E., \& Válková, H. (2003). Impact of inclusion in GPE on students without disabilities. Adapted Physical Activity Quarterly, 20(3), 230-245. doi:10. 1123/apaq.20.3.230

Oriel, K.N., Marchese, V.G., Shirk, A., Wagner, L., Young, E., \& Miller, L. (2012). The psychosocial benefits of an inclusive community-based aquatics program. Pediatric Physical Therapy, 24(4), 361-367. PubMed doi:10.1097/PEP.0b013e3182691792

Parker, J.G., \& Asher, S.R. (1987). Peer relations and personal adjustment: Are lowaccepted children at risk? Psychological Bulletin, 102(3), 357-389. PubMed doi:10. 1037/0033-2909.102.3.357

Pate, R.R., \& O’Neill, J.R. (2009). After-school interventions to increase physical activity among youth. British Journal of Sports Medicine, 43(1), 14-18. PubMed doi:10.1136/ bjsm.2008.055517

Reid, G. (2003). Defining adapted physical activity. In R.D. Steadward, G.D. Wheeler, \& E.J. Watkinson (Eds.), Adapted physical activity (pp. 11-24). Edmonton, AB, Canada: The University Press. 
Reid, G., Bouffard, M., \& MacDonald, C. (2012). Creating evidence-based research in adapted physical activity. Adapted Physical Activity Quarterly, 29(2), 115-131. PubMed doi:10.1123/apaq.29.2.115

Rimmer, J.H., Vanderbom, K.A., Bandini, L.G., Drum, C.E., Luken, K., Suarez-Balcazar, Y., \& Graham, I.D. (2014). GRAIDs: A framework for closing the gap in the availability of health promotion programs and interventions for people with disabilities. Implementation Science, 9(1), 100. PubMed doi:10.1186/s13012-014-0100-5

Sable, J. (1992). Collaborating to create an integrated camping program: Design and evaluation. Therapeutic Recreation Journal, 26(3), 38-48.

Scholl, K.G., McAvoy, L.H., Rynders, J.E., \& Smith, J.G. (2003). The influence of an inclusive outdoor recreation experience on families that have a child with a disability. Therapeutic Recreation Journal, 37(1), 38-57.

Scholl, K.G., Smith, J.G., \& Davison, A. (2005). Agency readiness to provide inclusive recreation and after-school services for children with disabilities. Therapeutic Recreation Journal, 39(1), 47-62.

Seymour, H., Reid, G., \& Bloom, G.A. (2009). Friendship in inclusive physical education. Adapted Physical Activity Quarterly, 26(3), 201-219. PubMed doi:10.1123/apaq.26. 3.201

Sirriyeh, R., Lawton, R., Gardner, P., \& Armitage, G. (2012). Reviewing studies with diverse designs: The development and evaluation of a new tool. Journal of Evaluation in Clinical Practice, 18(4), 746-752. PubMed doi:10.1111/j.1365-2753.2011.01662.x

Tremblay, M., \& Lloyd, M. (2010). Physical literacy measurement: The missing piece. Physical Health and Education Journal, 76, 26-30.

Turnnidge, J., Côté, J., Hollenstein, T., \& Deakin, J. (2014). A direct observation of the dynamic content and structure of coach-athlete interactions in a model sport program. Journal of Applied Sport Psychology, 26(2), 225-240. doi:10.1080/10413200.2013. 821637

Valentini, N.C., \& Rudisill, M.E. (2004). An inclusive mastery climate intervention and the motor skill development of children with and without disabilities. Adapted Physical Activity Quarterly, 21(4), 330-347. doi:10.1123/apaq.21.4.330

Vandell, D.L., Pierce, K.M., \& Dadisman, K. (2005). Out-of-school settings as a developmental context for children and youth. Advances in Child Development and Behavior, 33, 43-77. PubMed

Watkinson, E.J., \& Mulion, S. (1988). Playground skills of moderately mentally handicapped youngsters in integrated elementary schools. The Mental Retardation and Learning Disability Bulletin, 16(2), 204-219.

Wiecha, J.L., Beets, M.W., Colabianchi, N., Ferree, A., Hall, G., Hofman, J., \& Rauworth, A. (2014). Promoting physical activity in out-of-school-time programs: We built the bridge-Can we walk over it? Preventive Medicine, 69, S114-S116. PubMed doi:10. 1016/j.ypmed.2014.10.027

Wiley, K., \& Niedzielski-Eichner, N. (2017). Inclusive out-of-school time. Retrieved from http://www.nchpad.org/1294/6047/Inclusive Out-of-School Time

Wilhite, B., Devine, M.A., \& Goldenberg, L. (1999). Perceptions of youth with and without disabilities: Implications for inclusive leisure programs and services. Therapeutic Recreation Journal, 33(1), 15-28.

Zitomer, M.R., \& Reid, G. (2011). To be or not to be-able to dance: Integrated dance and children's perceptions of dance ability and disability. Research in Dance Education, 12(2), 137-156. doi:10.1080/14647893.2011.575224 